\title{
LEVANTAMIENTO BATIMÉTRICO DE LA PLANTA DE TRATAMIENTO DE AGUAS RESIDUALES DE NEVES PAULISTA
}

\section{BATHYMETRIC SURVEY OF THE NEVES PAULISTA SEWAGE TREATMENT PLANT}

\author{
Iván Andrés Sánchez Ortiz', Tsunao Matsumoto² \\ Fecha de recepción: 11 de agosto de 2013 \\ Fecha de aprobación: 15 de septiembre de 2014
}

Referencia: I.A. Sánchez Ortiz, T. Matsumoto. (2014). Levantamiento batrimétrico de la planta de tratamiento de aguas resiuales de Neves Paulista. Ciencia e Ingeniería Neogranadina, 24 (2), pp. 97-110

\section{RESUMEN}

Las lagunas de estabilización son uno de los sistemas naturales para tratamiento de aguas residuales más adecuados para reducir los impactos ambientales por vertimiento de efluentes en países en vías de desarrollo. La presente investigación tuvo como objetivo diagnosticar la acumulación de lodos y evaluar el desempeño de la planta de tratamiento de aguas residuales de la ciudad Neves Paulista (São Paulo, Brasil). Mediante un estudio batimétrico de las lagunas de estabilización anaerobia y facultativa se determinaron los perfiles y volúmenes de acumulación de lodos; se midieron diversos parámetros de la calidad del agua afluente y efluente, así como el caudal entrante durante 24 horas consecutivas. La batimetría indicó que los lodos acumulados redujeron los volúmenes útiles de las lagunas anaerobia y facultativa en $26,4 \%$ y $23,7 \%$ respectivamente y que su heterogénea distribución en las unidades de tratamiento afectó su desempeño hidráulico. La eficiencia media de remoción de la DBO fue del 76,6\%, inferior a la mínima establecida por la legislación ambiental brasilera. El número más probable de coliformes fecales en el efluente fue de $6,34 \times 10^{5} / 100 \mathrm{~mL}$, que superó en gran medida los valores máximos permitidos para vertimientos en cuerpos receptores. La planta requiere de la implementación de un sistema de pre-tratamiento, de la remoción de los lodos acumulados en las zonas más críticas y la implementación de un sistema de postratamiento que garantice remoción adicional de DBO y coliformes para ajustarse a la normatividad ambiental.

Palabras Clave: aguas residuales, lagunas de estabilización, batimetría, acumulación de lodo, calidad del efluente

1. Ingeniero Civil Esp. M.Sc. Profesor Asociado, Facultad de Ciencias Pecuarias. Universidad de Nariño, Pasto, Nariño, Colombia, iaso@udenar.edu. co

2. Ingeniero Civil M.Sc. y Ph.D. Profesor Adjunto Departamento de Ingeniería Civil. UNESP, Campus de Ilha Solteira, São Paulo, Brasil, tsunao@dec. feis.unesp.br 


\section{ABSTRACT}

Waste stabilization ponds are one of the most suitable natural wastewater treatment systems for reducing the environmental impacts produced by effluents dumping in developing countries. The objectives of this research were to diagnose the sludge accumulation and to evaluate the performance of the sewage treatment plant STP at Neves Paulista city (São Paulo, Brazil). Through a bathymetric study of the anaerobic and facultative lagoons, the profiles and volume accumulation of sludge were determined, different water quality parameters of the plant influent and effluent were measured, and the raw wastewater flow was measured during 24 consecutive hours. Pond bathymetry showed that the accumulated sludge reduced the working volumes of the anaerobic and facultative ponds in $26.4 \%$ and $23.7 \%$ respectively. Furthermore, the heterogeneous distribution in the lagoons affected their hydraulic performance. The average efficiency removal of BOD was $76.6 \%$, smaller than the minimum efficiency allowed by the Brazilian legislation. The effluent most probable number of fecal coliforms was $6.34 \times 10^{5} / 100 \mathrm{~mL}$, highly exceeding the maximum permitted values for dumping into receiving water bodies. The plant requires the implementation of a pretreatment system, the removal of accumulated sludge in the most critical zones, and the implementation of a post treatment system to guarantee additional BOD and fecal coliforms removal in order to adjust the efficiency to the environmental legislation standards.

Keywords: wastewater, stabilization ponds, bathymetry, sludge accumulation, effluent quality

\section{INTRODUCCIÓN}

Las plantas de tratamiento de aguas residuales (PTAR) se diseñan con el fin de alcanzar diferentes propósitos como proteger la salud pública, preservar el mejor uso del agua, proteger el suministro público del agua y proteger la vida acuática [1].

Una laguna de estabilización es la forma más sencilla para el tratamiento de aguas residuales (AR) y consiste en una estructura simple para embalsar aguas servidas con el objeto de mejorar sus características sanitarias [2-3]. Según Peña y Mara [4], las lagunas de estabilización son usualmente el más apropiado método para el tratamiento de AR domésticas y municipales en países en vías de desarrollo, donde el clima es más favorable para su operación. Estas presentan alta eficiencia y funcionamiento totalmente natural altamente sustentable; usualmente requieren bajos costos de inversión y poseen bajos costos de operación y mantenimiento [5]; de igual manera, asimilan grandes variaciones de caudal y realizan el tratamiento con eficiencias similares a las logradas por los sistemas convencionales, produciendo un efluente altamente purificado con costos muy inferiores [1].

Las lagunas de estabilización son utilizadas para tratamiento secundario de aguas residuales o como mecanismo de pulimento. Estas unidades de tratamiento se clasifican en facultativas, aerobias, anaerobias, aireadas, aireadas de alta tasa y de maduración [6].

El tratamiento de aguas residuales en lagunas de estabilización facultativas principalmente es el resultado de sedimentación y una 
compleja simbiosis entre bacterias y algas, donde la oxidación de la materia orgánica se logra a través de las bacterias en la presencia de oxígeno disuelto suministrado por la fotosíntesis algal y la reaireación superficial [7]. Por su parte, en las lagunas anaerobias el afluente entra en condiciones de anaerobiosis y soporta la biometanización (digestión anaerobia) de fracciones orgánicas complejas por parte de los microorganismos [8].

Los objetivos de este trabajo fueron diagnosticar la acumulación de lodos y evaluar el desempeño durante 24 horas consecutivas de la planta de tratamiento de aguas residuales (PTAR) de la ciudad Neves Paulista. Para ello se realizó un levantamiento batimétrico de las dos lagunas que conforman la planta y se midieron diversos parámetros de calidad del agua en el afluente y efluente de la PTAR. Con los resultados del estudio batimétrico detallado se determinaron los perfiles y volúmenes de sólidos sedimentados en las unidades de tratamiento y se identificaron las zonas de acumulación de lodo más críticas. El monitoreo de los parámetros permitió diagnosticar parcialmente el desempeño de la planta en términos de la remoción de materia orgánica (MO), organismos coliformes y sólidos, y se formularon recomendaciones para mejorar la calidad del efluente y adecuarlo a las directrices de remoción de demanda bioquímica de oxígeno y coliformes fecales definidas por la legislación brasilera.

\section{MATERIALES Y MÉTODOS}

\subsection{LOCALIZACIÓN Y CONFIGURACIÓN BÁSICA DE LA PTAR}

La ciudad de Neves Paulista se localiza en la región centro oeste del estado de São
Paulo en la latitud $20^{\circ} 50^{\prime} 48,35^{\prime \prime} S$ y longitud $49^{\circ} 37^{\prime} 49,54^{\prime \prime} \mathrm{W}$, a una altitud de 549 metros, donde según el Centro de pesquisas meteorológicas e climáticas aplicadas à agricultura [9] predomina el clima de sabana tropical -tipo Aw de acuerdo con la clasificación de Koeppen- con lluvias de verano y sequía de invierno, precipitaciones medias de $1355,5 \mathrm{~mm}$ anuales y temperatura promedio anual de 22,8 ${ }^{\circ} \mathrm{C}$. De acuerdo con los resultados del censo de 2010 reportados por el Instituto Brasileiro de Geografia e Estatística [10], el municipio posee una población de 8772 habitantes.

La PTAR fue implementada desde 1996. Para ello se adoptó como sistema de tratamiento dos lagunas de estabilización mediante laguna anaerobia seguida de una laguna facultativa. Hasta la fecha en la que se realizó la presente investigación la PTAR carecía de un sistema de pretratamiento pues no disponía de rejillas ni de un desarenador que retengan los sólidos de mayor tamaño ni los susceptibles de rápida sedimentación. La Figura 1 presenta una fotografía satelital en la que se observa la configuración básica de las dos lagunas y se indican los componentes básicos de la planta de tratamiento y los dos puntos de muestreo seleccionados para el estudio.

\subsection{CARACTERIZACIÓN DEL AFLUENTE CRUDO Y EFLUENTES DE LAS UNIDADES DE TRATAMIENTO}

Para registrar la variación de condiciones en un día promedio de la PTAR el estudio se hizo un día jueves y un viernes del mes de octubre. Se realizó el monitoreo del afluente crudo y el efluente final de la planta durante 24 horas consecutivas para así verificar la variación del desempeño de la PTAR y algunos parámetros importantes para su funcionamiento. Cabe mencionar que pese al alto nivel de importancia para el diagnóstico 


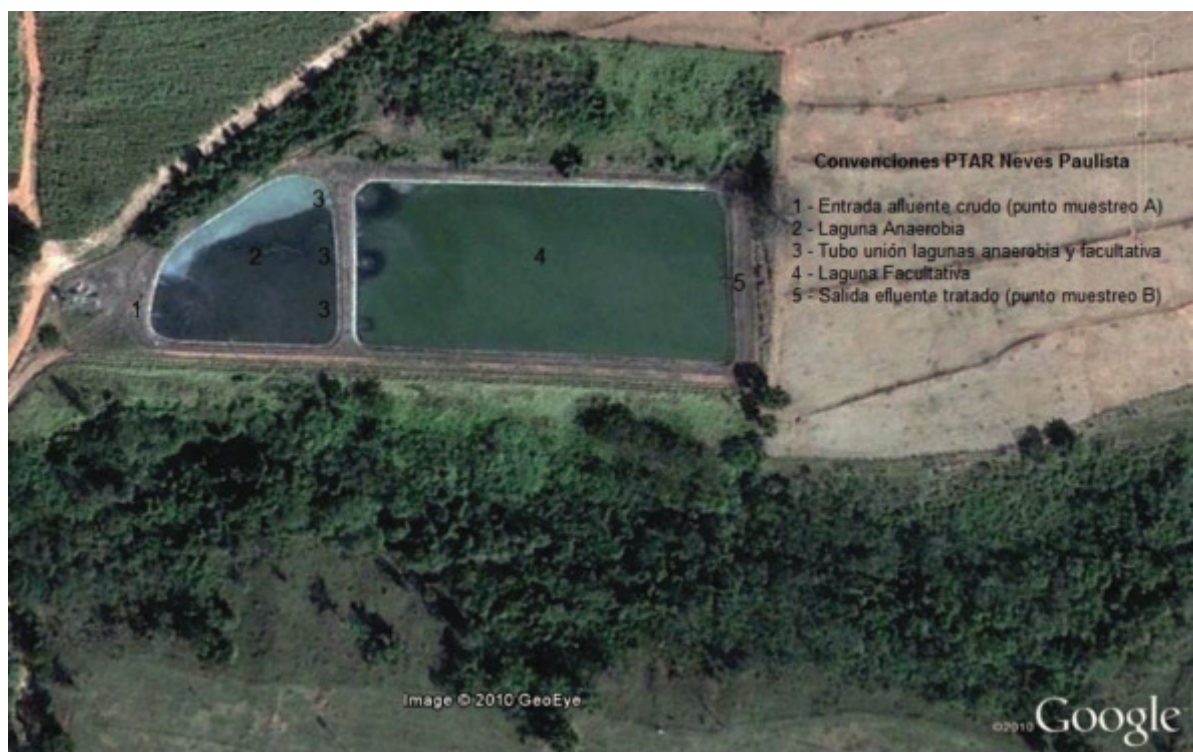

Figura 1. Fotografía satelital de la PTAR de Neves Paulista, puntos de muestreo.

Fuente: Google Earth, 2013.

de cada una de las unidades de tratamiento, no fue posible realizar mediciones al efluente de la laguna anaerobia (afluente laguna facultativa) debido a que los tubos que intercomunican las dos unidades de tratamiento (puntos referenciados con el número 3 en la Figura 1) se encuentran semisumergidos.

Los parámetros medidos en campo fueron caudal, $\mathrm{pH}$ y temperatura. Por su parte, en laboratorio y a partir de muestras tomadas cada hora se midió: demanda bioquímica de oxígeno (DBO), demanda química de oxígeno (DQO), número más probable de coliformes totales (NMPCT) y de coliformes fecales (NMPCF) por cada $100 \mathrm{~mL}$, sólidos totales (ST), fijos (STF) y volátiles (STV), sólidos suspendidos totales (SST), fijos (SSF) y volátiles (SSV).

Las mediciones in situ y la toma de muestras se realizaronenlos puntos 1 y 5 indicadosenlaFigura 1. Se utilizaron recipientes libres de impurezas e interferentes y se almacenaron en frascos de polipropileno y de polietileno transparente para su transporte y almacenamiento. Las muestras se almacenaron en cajas de icopor, se refrigeraron y se transportaron para su análisis en el Laboratorio de Saneamiento del Departamento de Ingeniería Civil de la Facultad de Ingeniería de la Universidade Estadual Paulista, Campus de Ilha Solteira.

La medición de los parámetros se basó en las metodologías de análisis definidas por APHA, AWWA y WEF [11] en las modalidades: analítica, colorimétrica y espectrofotométrica. El caudal afluente se determinó por medio de la medición de la columna de líquido que ingresó a la PTAR en tubo de concreto de diámetro 300 $\mathrm{mm}$; la temperatura y el $\mathrm{pH}$ se midieron con instrumentos portátiles.

\subsection{ESTUDIO BATIMÉTRICO}

Con el fin de determinar los perfiles de acumulación de sólidos sedimentados y a 
partir de ellos calcular la cantidad de lodo acumulado en el fondo de las lagunas y el volumen útil disponible en cada unidad se realizó su levantamiento batimétrico. Para la captura uniforme de datos batimétricos se definieron en la laguna anaerobia 12 perfiles longitudinales y 12 transversales espaciados a cada 5,0 m, con excepción del primer perfil longitudinal y el último perfil transversal cuya separación respecto al borde de la laguna fue de 2,5 m; en la laguna facultativa se definieron 13 perfiles longitudinales espaciados cada 5 $\mathrm{m}$, con excepción de los dos ubicados en los extremos laterales separados por 2,5 m de distanciay 16 perfiles transversales espaciados cada 10 metros, con excepción de los dos primeros y dos últimos espaciados a cada $5 \mathrm{~m}$. En total se realizaron mediciones batimétricas para 152 puntos en la laguna anaerobia y 208 puntos en la laguna facultativa.

Para mantener el alineamiento de los perfiles en terreno se utilizó una estación total y prismas reflectantes que permitieron orientar la dirección de una embarcación auxiliar. La obtención de los datos batimétricos de profundidad total de la laguna, profundidad de la columna de líquido y profundidad del lodo acumulado se realizó con astas metálicas y de PVC según lo descrito por Kellner et al. [12]. Con los datos obtenidos se elaboraron los perfiles del fondo de las lagunas y de acumulación de sedimentos, y se calcularon los volúmenes de lodo acumulados por medio de programas de diseño asistido por computadora.

\section{RESULTADOS Y DISCUSIÓN}

\subsection{BATIMETRÍA DE LA PTAR}

Las dimensiones en planta de la laguna anaerobia, de configuración trapezoidal con sección creciente en el sentido del flujo del agua son: base mayor $60,0 \mathrm{~m}$, base menor 27,5 m y altura de $62,5 \mathrm{~m}$ para un área superficial de $2718,8 \mathrm{~m}^{2}$, con profundidad media de 2,30 $\mathrm{m}$ y profundidad media del lodo acumulado de $0,47 \mathrm{~m}$.

El volumen teórico total calculado para la laguna sin acumulación de lodo fue de $6900 \mathrm{~m}^{3}$ y el volumen de sedimentos acumulado fue de 1821 $\mathrm{m}^{3}$; por ello, el volumen disponible (o útil) de la laguna para el momento de la investigación fue de $5079 \mathrm{~m}^{3}$.

La Figura 2 ilustra en una vista en planta la disposición de los ejes definidos para el estudio batimétrico y los perfiles transversales obtenidos para la laguna anaerobia.

Los perfiles evidencian una acumulación relativamente homogénea de los lodos, con excepción de la mayor presencia de estos en el sector inicial de la laguna y de manera especial en su lado derecho, lo que pudo deberse a que la distribución del flujo afluente no se realizó de manera equitativa por las dos tuberías de entrada en las que se subdividió el líquido después del punto de muestreo A (Figura 1). Adicionalmente a la heterogénea distribución del flujo, la ausencia de un pretratamiento del agua residual propicia la acumulación de sólidos de fácil sedimentación al inicio de la laguna anaerobia, situación que se aprecia con total claridad en la Figura 3, que presenta una fotografía de la zona de entrada donde se visualizan los montículos de material e inclusive la presencia de vegetación de gran tamaño.

La acumulación de lodos concentrada en ciertos lugares genera alteraciones en el desempeño hidráulico de la unidad de tratamiento y puede afectar de manera negativa el mantenimiento 
Ejes Longitudinales y Transversales para Levantamiento de la Laguna Anaerobia

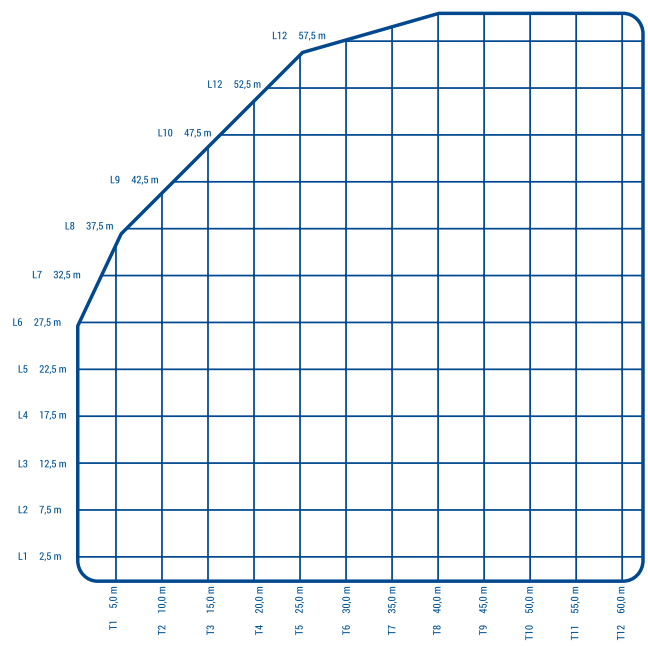

Perfiles Transversales de la Laguna Anaerobia
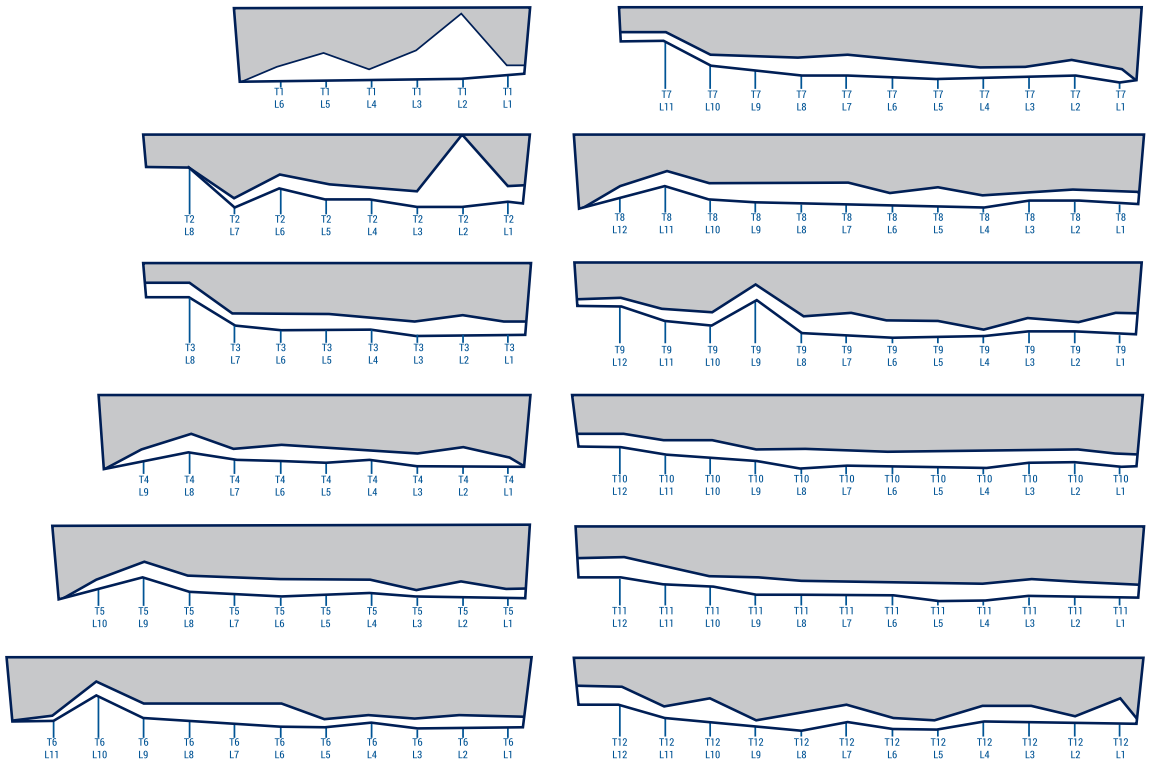

Figura 2. Vista en planta y perfiles transversales de la laguna anaerobia.

de las condiciones de diseño de la laguna en cuanto a su tiempo de retención hidráulica (TRH), ello debido a que la formación de zonas muertas y caminos preferenciales reducen el tiempo de permanencia del líquido en la laguna.
Por su parte, la laguna facultativa posee un largo de $150,0 \mathrm{~m}$ y un ancho de $60,0 \mathrm{~m}$, lo que representa un espejo de agua de 9000 $\mathrm{m}^{2}$, la profundidad media de la unidad de tratamiento fue de 1,05 m, con altura media 


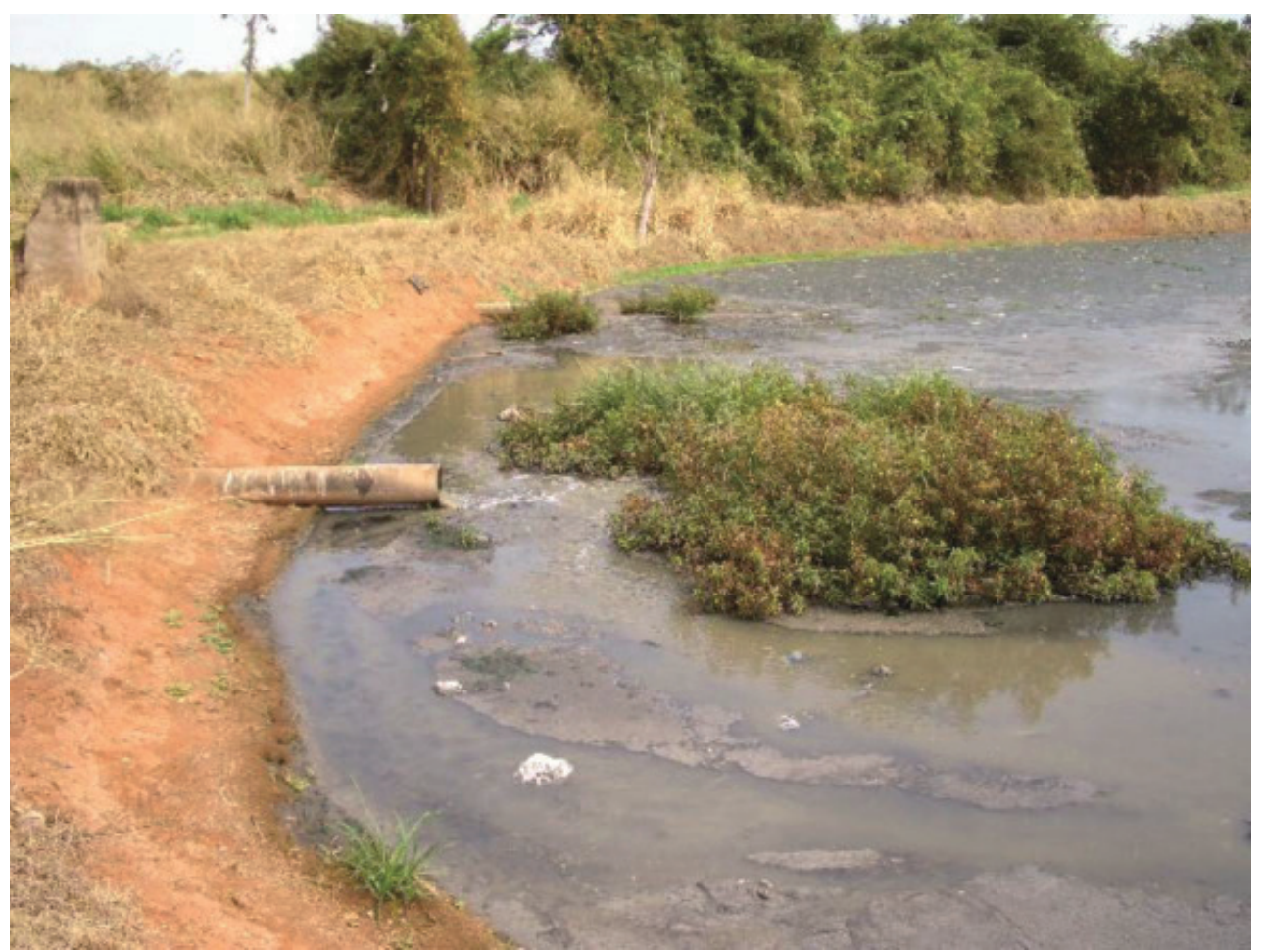

Figura 3. Detalle de la zona de entrada a la laguna anaerobia.

del lodo acumulado de 0,25 m. El volumen teórico total estimado para la laguna fue de $9500 \mathrm{~m}^{3}$ y el del lodo acumulado fue de $2250 \mathrm{~m}^{3}$, lo que representó un volumen útil disponible de $7250 \mathrm{~m}^{3}$.

La Figura 4 ilustra la vista en planta de la disposición de los ejes utilizados en el estudio batimétrico y los perfiles transversales obtenidos para la laguna facultativa.

Como se puede observar en la Figura 4, la laguna facultativa también presentó una acumulación relativamente homogénea de sedimentos en la mayor parte de su extensión, con excepción del tercio inicial y con un ligero énfasis en su parte derecha como consecuencia del mayor flujo afluente en el tubo derecho de la laguna anaerobia. La mayor concentración de los sedimentos en las zonas cercanas a los puntos de ingreso del afluente sugiere su labor de pulimento en la sedimentación de sólidos que eventualmente escapan de la laguna anaerobia, como resultado de la reducción en su TRH anteriormente comentada.

\subsection{CARACTERIZACIÓN DEL AFLUENTE Y EFLUENTE DE LA PTAR}

Los valores promedio con las correspondientes desviaciones típicas calculados para los parámetros analizados tanto en el afluente crudo como para el efluente final se presentan en la Tabla 1 y se discutirán en detalle más adelante. 
Ejes Longitudinales y Transversales para Levantamiento de la Laguna Facultativa

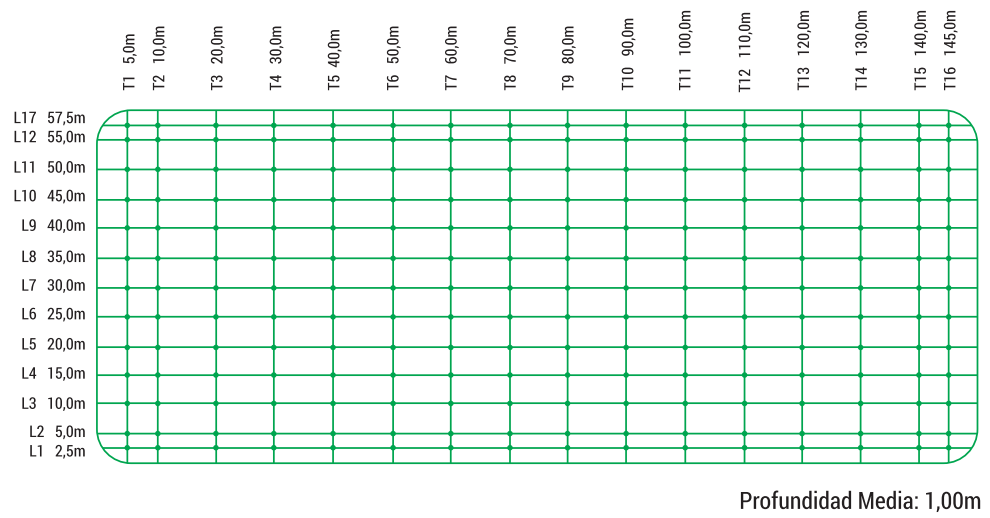

Perfiles Transversales de la Laguna Anaerobia

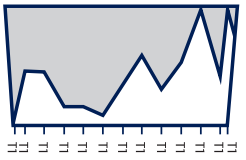

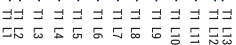
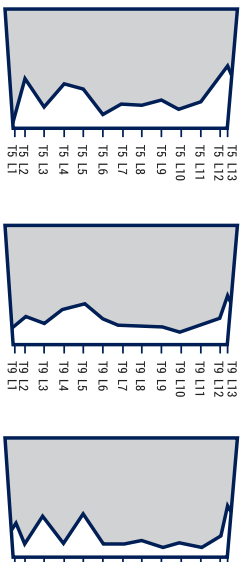

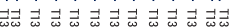

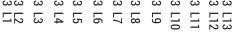
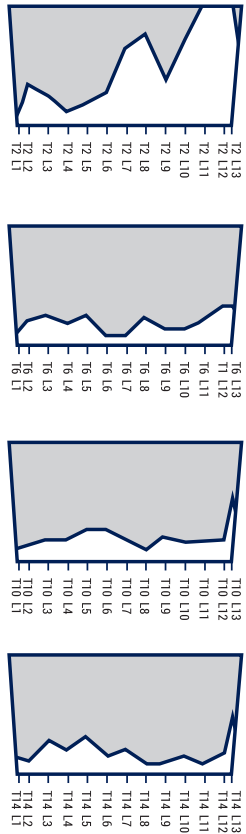
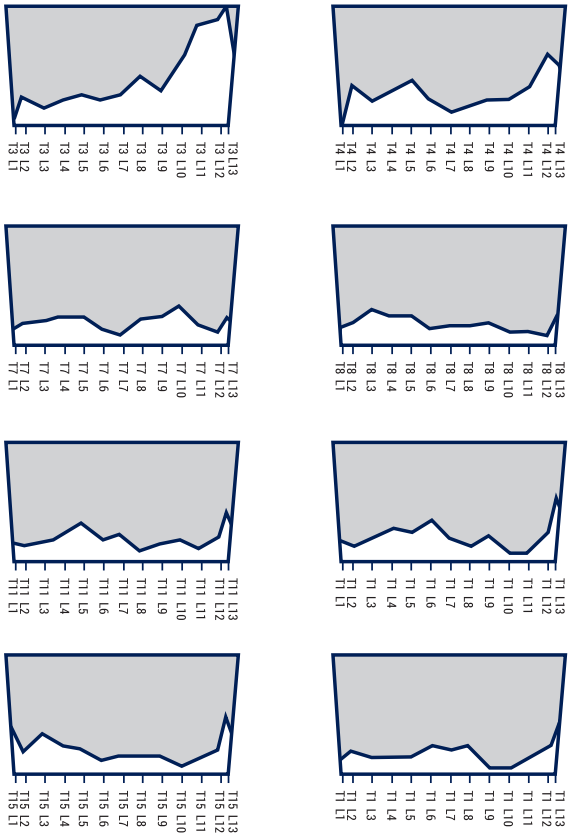

Figura 4. Vista en planta y perfiles transversales de la laguna facultativa.

\subsubsection{Variación del caudal}

En la Figura 5 se presenta la variación de las concentraciones de la DBO y DQO afluentes así como el caudal que ingresó a la PTAR a lo largo de las 24 horas del monitoreo.
El caudal afluente a la PTAR presentó valores pico en horario de la mañana, al medio día y en el final de la tarde e inicio de la noche, ajustándose así a la variación diaria típica reportada en la literatura. El flujo afluente osciló entre 1,4 y $14,5 \mathrm{~L} / \mathrm{s}$, con un valor medio 
Tabla 1. Valores medios y desviación estándar de las características del afluente y efluente de la PTAR de Neves Paulista.

\begin{tabular}{|l|c|c|}
\hline \multicolumn{1}{|c|}{ Parámetros } & Afluente crudo & Efluente final \\
\hline $\mathrm{pH}$ & $7,13 \pm 0,25$ & $7,71 \pm 0,57$ \\
\hline Temperatura $\left({ }^{\circ} \mathrm{C}\right)$ & $28,3 \pm 1,57$ & $28,0 \pm 2,54$ \\
\hline $\mathrm{DQO}(\mathrm{mg} / \mathrm{L})$ & $786,4 \pm 561,2$ & $281,6 \pm 105,2$ \\
\hline $\mathrm{DBO}(\mathrm{mg} / \mathrm{L})$ & $319,2 \pm 129,0$ & $74,5 \pm 37,9$ \\
\hline Coliformes totales $(\mathrm{NMP} / 100 \mathrm{~mL})$ & $1,88 \times 10^{8} \pm 2,7 \times 10^{8}$ & $3,12 \times 10^{6} \pm 2,0 \times 10^{6}$ \\
\hline Coliformes fecales $(\mathrm{NMP} / 100 \mathrm{~mL})$ & $2,55 \times 10^{7} \pm 5,6 \times 10^{7}$ & $6,34 \times 10^{5} \pm 4,1 \times 10^{5}$ \\
\hline Sólidos totales $(\mathrm{mg} / \mathrm{L})$ & $647,7 \pm 200,6$ & $478,2 \pm 158,1$ \\
\hline Sólidos totales fijos $(\mathrm{mg} / \mathrm{L})$ & $242,8 \pm 51,5$ & $202,5 \pm 74,1$ \\
\hline Sólidos totales volátiles $(\mathrm{mg} / \mathrm{L})$ & $404,9 \pm 166,6$ & $275,7 \pm 100,8$ \\
\hline Sólidos suspendidos totales $(\mathrm{mg} / \mathrm{L})$ & $309,4 \pm 112,4$ & $288,0 \pm 81,7$ \\
\hline Sólidos suspendidos fijos $(\mathrm{mg} / \mathrm{L})$ & $92,5 \pm 55,0$ & $112,2 \pm 49,6$ \\
\hline Sólidos suspendidos volátiles $(\mathrm{mg} / \mathrm{L})$ & $216,9 \pm 79,9$ & $175,8 \pm 44,3$ \\
\hline
\end{tabular}

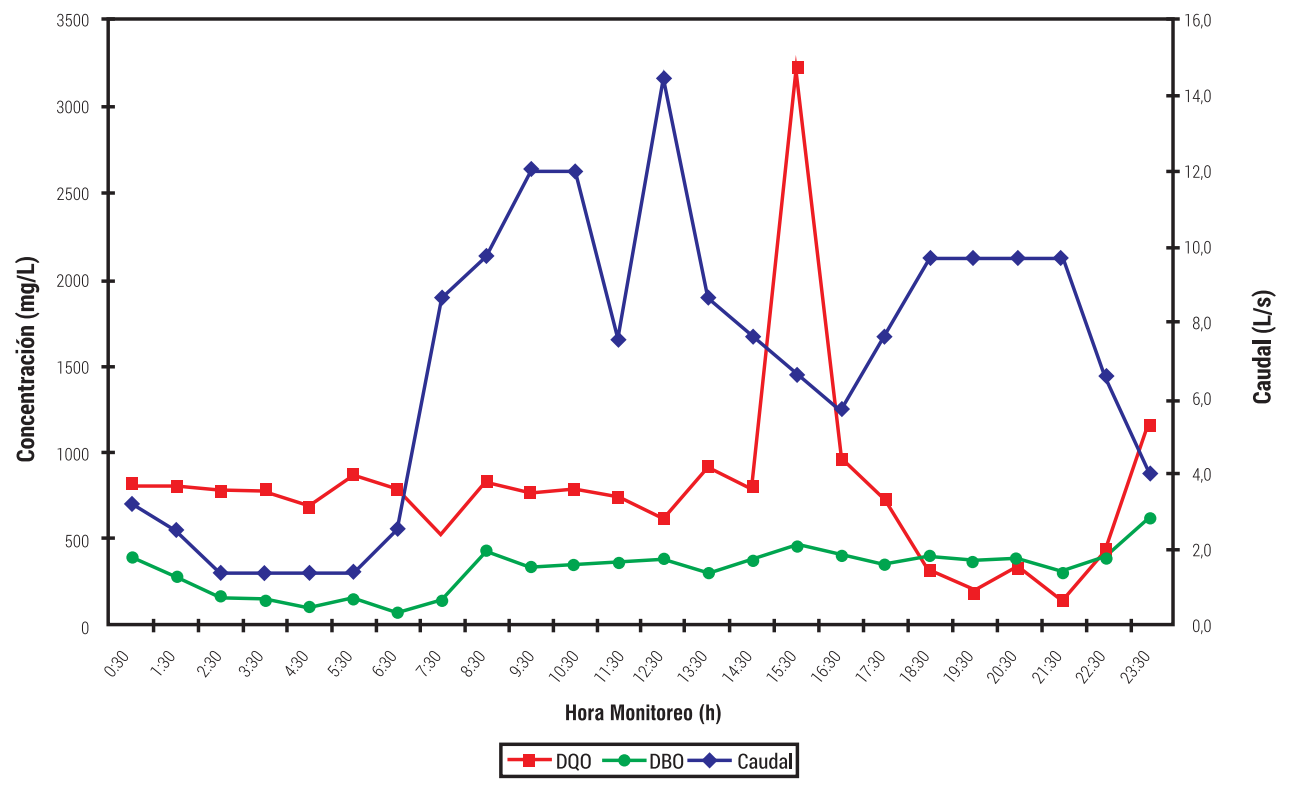

Figura 5. Variación del caudal, DQO y DBO afluentes a la PTAR a lo largo de 24 h.

calculado de 7,0 $\pm 3,83 \mathrm{~L} / \mathrm{s}$; o sea, un caudal Con base en los volúmenes útiles disponibles diario de aproximadamente $604,8 \mathrm{~m}^{3} / \mathrm{d}$. de 5079 y $7250 \mathrm{~m}^{3}$ en las lagunas anaerobia 
y facultativa anteriormente calculados y considerando el caudal promedio se determinó que el TRH total de la laguna anaerobia fue de $8,4 \mathrm{~d}$ y el de la facultativa de $11,9 \mathrm{~d}$, para un total de 20,3 d en la PTAR. EI TRH de la laguna anaerobia fue mayor al recomendado por von Sperling [3] de 3,0 a 6,0 días y Sant'Anna Jr. [13] entre 2,0 y 5,0 días. En el caso de la facultativa se encontró en el rango de valores recomendado por von Sperling [3] entre 7,5 y 22,5 días e inferior al máximo recomendado por Menya et al. [14] de 30 días. Los tiempos de retención de los dos tipos de lagunas son inferiores a los rangos recomendados por Crites y Tchobanoglous [15] de 20 a 50 d para lagunas anaerobias y entre 25 y $180 \mathrm{~d}$ para las facultativas.

\subsubsection{DBO y DQO}

La concentración de la DBO afluente a la planta varió entre 67 y $626 \mathrm{mg} / \mathrm{L}$ con promedio de $319 \mathrm{mg} / \mathrm{L}$, mientras que la DQO varió entre 141 y $3216 \mathrm{mg} / \mathrm{L}$ con promedio de $786 \mathrm{mg} / \mathrm{L}$. Con los datos registrados se verificó que la relación existente entre las concentraciones de la DQO y la DBO afluentes fue de 2,46, ligeramente superior a las relaciones típicas reportadas por autores como Metcalf y Eddy [16]. Cabe mencionar que la alta variabilidad de los datos de la DQO, reflejada en los valores máximo y promedio, y la correspondiente desviación estándar (Tabla 1) fueron altamente influenciadas por el valor pico registrado en torno de las 3 p.m., que pudo ser fruto del vertimiento de algún tipo de efluente de las pequeñas industrias de productos lácteos propias del municipio.

A partir de las concentraciones medias de DBO y DQO y el caudal promedio afluente se estimaron los valores de la carga orgánica aplicada a la planta que fueron de 192,9
$\mathrm{kgDBO} / \mathrm{d}$ y de $475,4 \mathrm{kgDQO} / \mathrm{d}$. Para calcular la carga orgánica volumétrica que ingresó a la PTAR se consideró el volumen útil efectivo disponible de la laguna anaerobia y el valor de DBO afluentes, se estimó del orden de $0,038 \mathrm{~kg} \mathrm{DBO} / \mathrm{m}^{3} / \mathrm{d}$, superior al mínimo recomendado por Sant'Anna Jr. [13], de 0,04 a $0,08 \mathrm{kgDBO} / \mathrm{m}^{3} / \mathrm{d}$, y sobrepasa ligeramente el rango superior recomendado por von Sperling [3], entre 0,01 y $0,35 \mathrm{kgDBO} / \mathrm{m}^{3} / \mathrm{d}$, pero se encuentra por debajo del valor máximo definido por Romero [17], de hasta $0,40 \mathrm{kgDBO} / \mathrm{m}^{3} / \mathrm{d}$.

Tal como se comentó anteriormente, no fue posible realizar el análisis específico del efluente de la laguna anaerobia (afluente laguna facultativa). Por tal razón, para analizar la carga orgánica superficial que pudo ingresar a la segunda laguna se estimó una eficiencia de remoción de DBO relativamente baja del $50 \%$-menor al $70 \%$ sugerido por Mara [18] para lagunas anaerobias bajo temperaturas superiores a los $25^{\circ} \mathrm{C}$-. Con base en lo anterior se tiene que la concentración media estimada fue de $96,5 \mathrm{mg} / \mathrm{L}$ de DBO afluente y utilizando el caudal medio se tiene que la carga diaria calculada fue de $64,9 \mathrm{kgDBO} / \mathrm{ha} / \mathrm{d}$ para un área superficial de $9000 \mathrm{~m}^{2}$, valor inferior a la tasa límite de $150 \mathrm{kgDBO} / \mathrm{ha} / \mathrm{d}$ recomendada por Nuvolari [19] y a los rangos recomendados por von Sperling [3] para zonas con invierno caliente y alta insolación, entre 240 y $300 \mathrm{kgDBO} / \mathrm{ha} / \mathrm{d}$.

En el efluente final de la PTAR, los valores medidos de DBO variaron entre 36 y 153 $\mathrm{mg} / \mathrm{L}$, con promedio de $74,5 \mathrm{mg} / \mathrm{L}$, lo que representa una eficiencia de remoción media total de la DBO en torno de $76,65 \%$, menor al mínimo porcentaje recomendado por el Decreto 8464 del estado de São Paulo [20] y con una concentración media que supera a la máxima recomendada de $60 \mathrm{mg} / \mathrm{L}$. La DQO del efluente final varió entre 183 y 525 
$\mathrm{mg} / \mathrm{L}$ con promedio de $281,6 \mathrm{mg} / \mathrm{L}$. Aunque se registraron importantes eficiencias en la remoción de la MO, los valores calculados no satisfacen los requisitos que establece la legislación ambiental brasilera, ello pudo deberse al flujo preferencial en la laguna anaerobia que puede incidir sobre el real TRH de dicha unidad. De igual manera, los desfases en los valores de las cargas volumétricas y de aplicación superficial con respecto a los rangos recomendados por la literatura pudieron incidir en el desempeño de las unidades de tratamiento. Es probable que las dimensiones otorgadas al sistema de tratamiento hayan obedecido a un panorama de crecimiento poblacional mayor al que efectivamente ha experimentado Neves Paulista, generando condiciones de sobredimensionamiento. Se recomienda implementar un postratamiento que contribuya a la remoción adicional de MO para reducir el impacto ambiental sobre el cuerpo receptor y ajustar las eficiencias de desempeño de la PTAR a las directrices ambientales.

\subsection{3. $\mathrm{pH}$}

El pH del afluente registró valores que variaron entre 6,7 y 8,0 y en el efluente final varió entre 7,1 y 9,1 . En términos de los valores medios, el $\mathrm{pH}$ medido fue superior al valor de neutralidad (Tabla 1), pues aunque en el afluente se evidenciaron valores ligeramente ácidos, al interior de los sistemas de tratamiento por lagunas de estabilización los procesos fotosintéticos presentes, sobre todo en las lagunas facultativas, incrementan el $\mathrm{pH}$ del líquido.

\subsubsection{Temperatura}

La temperatura medida en el afluente de la PTAR osciló entre 25,2 y $30,6^{\circ} \mathrm{C}$ mientras que el efluente de la laguna facultativa registró valores que variaron entre 25,3 y $33,6^{\circ} \mathrm{C}$. La pequeña reducción de los valores medios se debió al descenso de temperatura en el horario nocturno que le resta calor a la masa de agua de las lagunas.

\subsubsection{Coliformes totales y fecales}

En los exámenes bacteriológicos realizados al afluente y efluente, se determinó que la variación del NMP de CT/100mL en el afluente osciló entre $3,00 \times 10^{5}$ y $9,00 \times 10^{8}$ y en el efluente de la laguna facultativa entre $1,00 \times 10^{5}$ y $7,60 \times 10^{6}$; y la variación del NMP de $C F / 100 \mathrm{~mL}$ fue de $2,37 \times 10^{4} \mathrm{a}$ $2,00 \times 10^{8}$ en el afluente y de $7,00 \times 104$ a $1,70 \times 10^{6}$ en el efluente final de la planta. Los valores de la Tabla 1 permitieron determinar que la remoción media de CT fue del $98,3 \%$ y de CF del $97,5 \%$, en ambos casos inferior a dos unidades logarítmicas de remoción de los microorganismos. La cantidad de CF del efluente final, cuyo valor medio fue de $6,34 \times 10^{5} / 100 \mathrm{~mL}$ supera en gran medida el valor establecido por la legislación ambiental para el estado de São Paulo, pues el Decreto Estatal $n^{\circ}$ 8468 [20] exige que para vertimiento de efluentes en cuerpos de agua receptores Clase 2 el NMP debe ser máximo de $1000 \mathrm{CF} / 100 \mathrm{~mL}$.

\subsubsection{Sólidos}

En el afluente crudo los ST oscilaron entre 338 y $1306 \mathrm{mg} / \mathrm{L}$, con 144 a $382 \mathrm{mg} / \mathrm{L}$ de STF y 182 a 924 mg/L de STV. En el efluente final las concentraciones variaron de 350 a $982 \mathrm{mg} / \mathrm{L}$ de ST, con 94 a 462 mg/L de STF y de 190 a 524 $\mathrm{mg} / \mathrm{L}$ de STV. Las concentraciones medidas tuvieron un comportamiento relativamente uniforme, con excepción de picos registrados en las muestras tomadas al medio día, a las 3 de la tarde y las 7 de la noche, los cuales incidieron en el aumento de la desviación estándar calculada. Los valores registrados 
en la Tabla 1 sugieren un bajo desempeño en la remoción de sólidos por parte del sistema, pues la eficiencia media de remoción de ST fue del $26,2 \%$. Sin embargo, la acumulación de lodo reflejada en los perfiles batimétricos indica que la PTAR remueve una importante cantidad de material sedimentable, situación que también se refleja en la estabilización de la materia orgánica. Las altas concentraciones de sólidos en el efluente final pueden atribuirse a la elevada presencia de algas existente a la salida de la laguna facultativa.

Las concentraciones de SST en el afluente oscilaron entre 136 y $640 \mathrm{mg} / \mathrm{L}$, divididos entre SSF de 20 a 268 mg/L, y SSV de 92 a 380 mg/L. En el efluente final la variación fue entre 146 y $428 \mathrm{mg} / \mathrm{L}$, con 18 a $208 \mathrm{mg} / \mathrm{L}$ de SSF y 92 a $256 \mathrm{mg} / \mathrm{L}$ de SSV. Los resultados muestran que la planta removió este componente de los sólidos afluentes en un valor medio del orden del 6,9\%. Según Bolton et al. [21], la eficiencia de fotoinactivación de microorganismos como los coliformes en lagunas de estabilización suele ser afectada por la alta presencia de SS. Tal situación pudo incidir en la baja eficiencia reportada por la planta en la remoción de coliformes fecales.

Con el fin de mejorar el desempeño de la PTAR encuanto a la estabilización de materia orgánica y coliformes fecales, es necesario incorporar en el tren de tratamiento alternativas de postratamiento que complementen la labor de remoción de la DBO y que reduzcan de forma más contundente el NMP de coliformes fecales en el efluente final. Algunas de las opciones para ello son la implantación de sistemas de tratamiento físico químico, la inclusión de sistemas naturales altamente eficientes como humedales construidos o el aprovechamiento de la alta radiación solar de la zona por medio de lagunas de maduración.

\section{CONCLUSIONES}

Elestudiobatimétrico reportóuna distribución heterogénea de los lodos sedimentados en las dos lagunas de estabilización, los volúmenes representaron una reducción de cerca del $25 \%$ del volumen útil de la planta de tratamiento.

La eficiencia de remoción de la DBO en la PTAR fue menor al 80\% mínimo exigido por la legislación ambiental para el estado de São Paulo pues reportó un valor medio del 76,6\%. La concentración media de DBO en el efluente final fue de $74,5 \mathrm{mg} / \mathrm{L}$, valor que superó el máximo permitido por la legislación estatal cuyo valor límite es de $60 \mathrm{mg} / \mathrm{L}$.

El NMP promedio calculado de coliformes fecales en el efluente final de la PTAR fue de $6,34 \times 105 / 100 \mathrm{~mL}$, que superó en gran medida el máximo permitido por la legislación de 1000 CF/100mL.

La planta requiere incorporar en el tren de tratamiento un sistema de pretratamiento que remueva los sólidos flotantes y de fácil sedimentación presentes en el afluente crudo. Así mismo, requiere de la remoción controlada de los lodos acumulados en las zonas más críticas para favorecer el funcionamiento hidráulico de las lagunas.

Para que la PTAR cumpla con las directrices ambientales sobre vertimiento de efluentes deberán implementarse unidades de tratamiento complementarias que contribuyan a la remoción adicional de materia orgánica y de coliformes fecales por medio de sistemas de tratamiento con algún nivel de mecanización o de tipo natural, como los humedales construidos o las lagunas de maduración. 


\section{REFERENCIAS BIBLIOGRÁFICAS}

[1] Spellman, F.R. (2009). Handbook of Water and Wastewater Treatment Plant Operators (Second Edition). Boca Raton, FL, EE.UU.: CRC Press Taylor and Francis Group, p.825.

[2] Organización Panamericana de la Salud -OPS- \& Centro Panamericano de Ingeniería Sanitaria y Ciencias Ambientales -CEPIS-. (2005). Guía para el diseño de tanques sépticos, tanques Imhoff y lagunas de estabilización. Lima, Perú: OPS, CEPIS, p.40.

[3] von Sperling, M. (2009). Lagoas de Estabilização - Princípios do Tratamento Biológico de Águas Residuárias, v.3 (2 Edição ampliada). Belo Horizonte, Brasil: Departamento de Engenharia Sanitária e Ambiental da Universidade Federal de Minas Gerais (DESA/UFMG), p.196.

[4] Peña, M. \& Mara, D. (2004). Waste Stabilisation Ponds. Países Bajos: IRC International Water and Sanitation Centre, p.37.

[5] Sah, L., Rousseau, D. \& Hooijmans, C. (2012). Numerical Modelling of Waste Stabilization Ponds: Where Do We Stand? Water, Air \& Soil Pollution, 223, pp.3155-3171.

[6] Bitton, G. (2005). Wastewater microbiology (Third edition). New Jersey, EE.UU: John Wiley \& Sons Inc., p.746.

[7] Beran, B. \& Kargi, F. (2005). A dynamic mathematical model for wastewater stabilization ponds. Ecological Modelling, 181, pp.39-57.
[8] Cardinali-Rezende, J., Pereira, Z., Sanz, J., Chartone-Souza, E. \& Nascimento, A. (2012). Bacterial and archaeal phylogenetic diversity associated with swine sludge from an anaerobic treatment lagoon. World Journal of Microbiology and Biotechnology, 28, pp.3187-3195.

[9] Centro de pesquisas meteorológicas e climáticas aplicadas à agricultura CEPAGRI. (2012). Clima dos municípios paulistas. Recuperado en julio de 2013, de http://www.cpa.unicamp.br/outrasinformacoes/clima_muni_367.html

[10] Instituto Brasileiro de Geografia e Estatística - IBGE. Censo Demográfico 2010 - Resultados do universo. Recuperado en agosto de 2013, de http:// www.ibge.gov.br/cidadesat/xtras/perfil. php?codmun $=353250 \&$ search $=$ sao paulo|neves-paulista

[11] APHA, AWWA \& WEF. (2005). Standard Methods for the Examination of Water and Wastewater (21st ed.). Washington, D.C., EE.UU.: American Public Health Association, p.1368.

[12] Kellner, E., Moreira, J.F. \& Pires, E.C. (2009). Influência da estratificação térmica no volume útil e no comportamento hidrodinâmico de lagoa de estabilização: determinação experimental e teórica. Revista Engenharia Sanitária e Ambiental, 14(1), pp.129-138.

[13] Sant'Anna Jr., G.L. (2010). Tratamento biológico de efluentes: Fundamentos e aplicações. Rio de Janeiro, Brasil: Editora Interciência, p.418.

[14] Menya, E., Wangi, G.M., Amanyire, F. \& Ebangu, B. (2013). Design of waste 
stabilization ponds for dairy processing plants in Uganda. Agricultural Engineering International: CIGR Journal, 15(3), pp.198-207.

[15] Crites, R. \& Tchobanoglous, G. (2000). Tratamiento de aguas residuales en pequeñas poblaciones. Bogotá, Colombia: McGraw Hill, p.776.

[16] Metcalf \& Eddy. (2004). Wastewater Engineering: Treatment and Reuse (Fourth edition, International edition). Singapur: McGraw Hill, p.1820.

[17] Romero, R.J.A. (2010). Tratamiento de aguas residuales. Teoría y principios de diseño (Tercera edición). Bogotá, Colombia: Editorial Escuela Colombiana de Ingeniería, p.1248.

[18] Mara, D. (2004). Domestic Wastewater Treatment in Developing Countries (First edition). Londres, Inglaterra: Earthscan Ed, p.293.

[19] Nuvolari, A. (2003). Esgoto sanitário. Coleta, transporte tratamento e reúso. São Paulo, Brasil: Editorial Edgard Blücher Ltda., p.520.

[20] São Paulo. (1976). Decreto Estadual $n^{\circ}$ 8.468, de 8 de setembro de 1976 . Aprova o Regulamento da Lei $n^{\circ} 997$, de 31 de maio de 1976, que dispõe sobre a Prevenção e o Controle da Poluição do Meio Ambiente. Recuperado em julio de 2013, de http://www.cetesb.sp.gov.br/ Institucional/documentos/Dec8468.pdf

[21] Bolton, N.F., Cromar, N.J., Buchanan, N.A. \& Fallowfield, H.J. (2011). Variations in sunlight attenuation in waste stabilisation ponds and environmental waters. En: Proceedings of the 9th IWA Specialist Group Conference on Waste Stabilisation Ponds 1-3 August 2011. Adelaide, Australia: IWA. 